\title{
Bearing Fault Detection in Induction Machine Based on Stator Current Spectrum Monitoring
}

\author{
Makoto Kanemaru $^{* a)} \quad$ Member, $\quad$ Mitsuru Tsukima* ${ }^{* *}$ Member \\ Toshihiko Miyauchi $^{* * *}$ Non-member, Kazufumi Hayashi ${ }^{* * *}$ Non-member
}

\begin{abstract}
Bearing faults account for a large majority of the faults in a three-phase induction motor. Recently, many research activities were focused on the diagnosis of bearing faults by motor current signature analysis. However, the effective frequency band is not fully understood in terms of the diagnosis of the bearing fault. Moreover, the temporal change in motor stator current spectrum with faulty bearing has not been sufficiently investigated. The purpose of this paper is to clarify the characteristic frequency band and to evaluate the temporal change in the power spectral density of stator current by using powder contaminated bearing before complete halt of the motor. Experiments were performed with normal and powder contaminated bearings in the induction motor. The diagnosis technique for the powder contaminated bearing is discussed based on the experimental results.
\end{abstract}

Keywords: induction motor, powder contaminated bearing, stator current power spectral density, bearing fault frequency, rotational frequency, fault detection

\section{Introduction}

Motors are key components in production plants, playing an important role in powering production line facilities and mechanical equipment. At steel-making and petrochemical plants, motors play a part in many pieces of equipment, in processes all the way from unloading raw materials to shipping products. Motors must be capable of running continuously in normal and stable operations. However, not all motors run in normal environments, and in many cases they are operating under high-stress conditions, such as high temperatures, heavy loads, corrosion and abrasion. In some production plant facilities, equipment runs continuously 24 hours a day, and their motors operate under heavy loads. Sudden motor malfunctions lead directly to production line shutdowns and worsening of product yields, causing business losses. In order to avoid this type of sudden breakdown stoppage, plants at all companies keep maintenance staff permanently allocated. However, in recent years, because of the need for business efficiency, there has been a trend toward reducing equipment maintenance costs and labor-saving maintenance. Furthermore, with generational change there has been a decrease in inspection skills and a trend towards amateurization. Increasingly, situations exist where continuous stable

a) Correspondence to: Makoto Kanemaru. E-mail: Kanemaru. Makoto@cw.MitsubishiElectric.co.jp

* Advanced Technology R\&D Center, Mitsubishi Electric Corp. 8-1-1, Tsukaguchi-Honmachi, Amagasaki, Hyogo 661-8661, Japan

** Osaka Electro-Communication University

18-8, Hatsucho, Neyagawa, Osaka 572-8530, Japan

${ }^{* * *}$ Power Distribution System Center, Mitsubishi Electric Corp. 8, Horai-cho, Marugame, Kagawa 763-8516, Japan operation of motors cannot be expected. Therefore, there is now a strong need for motor degradation diagnosis technology that does not rely on the skill level of maintenance personnel.

The results of a survey of types of motor degradation show that bearing faults at $41-44 \%$ are the most frequent ${ }^{(1)}$. Therefore, multiple bearing fault diagnosis technologies have been established. They are classified into four major categories below $^{(2)}$.

(1) Inspection using the five senses: temperature measurement by touch and electronic listening stick method

(2) Mechanical signal analysis method: Oscillation acceleration method and ultrasonic vibration method

(3) Electrical signal method: Current interlinkage method

(4) Lubricant analysis method: Analysis of abrasive particles in lubricant

Of these, the method with the highest practicality and highest level of maturity is the mechanical signal analysis method. The mechanical signal analysis method enables the identification of bearing faults by focusing on natural frequencies with minute vibrations that cannot be heard by the human ear.

Recently research is being done on MCSA (Motor Current Signature Analysis), which is a sophisticated version of the electrical signal method ${ }^{(3)-(13)}$. It is based on the effect that the changes in the air gap between the stator and the rotor have on the spatial magnetic field lines. The congruency of vibrational harmonics and current harmonic caused by abnormal bearings was reported in $1995^{(3)}$. In addition to enabling the detection of bearing abnormalities, it has been discovered theoretically that it is possible to detect current harmonics 
due to uneven gaps, rotor damage and loads ${ }^{(14)}$

Furthermore, bearing fault detection was attempted by applying a low pass filter and Root-MUSIC algorithm to electrical signals, and performing instantaneous frequency Fourier transformation ${ }^{(15)}$. The purpose was to use signal processing analysis for early detection of bearing faults, but there was weak signal strength in the frequency analysis results, and early detection was not possible. In 2008, Park's Vector Approach, which converted three-phase to two-axis for analysis, was used to study bearing fault detection ${ }^{(16)(17)}$. In 2011, a diagnostic technology was reported that focused on the low frequency range of near power line frequencies with load currents ${ }^{(18)}$. A relationship between current frequency analysis waveform disturbance and the state of bearings was demonstrated.

These studies show that it is possible to detect bearing faults by analysis of motor current frequency. However, this technology does not have practical application for detecting bearing faults while a machine is running, in real time. There are two reasons for this. First is that there is no clear signal frequency band that is effective for observing bearing faults. Second, the temporal characteristics of signal strengths as the deterioration progresses are not clear, and whether detection is possible has not been validated.

The purpose of this study is to identify the current signal frequency band that is effective for bearing degradation diagnosis, and to validate a proposed diagnostic method. For our experiment, we manufactured contaminated bearings. Then we measured the stator current power spectral density when a motor that had contaminated bearings installed was operated. Then, we identified the signal frequency band effective for observation of bearing faults, and proposed a bearing fault diagnosis method. Finally, using a motor with accelerated degradation, we validated the utility of this method.

\section{Contaminated Bearings}

2.1 Motor and Bearing Specifications The specifications for bearings installed in motors differ according to the motor rating type. Table 1 shows motor ratings and nominal bearing numbers. When the rated output of a motor is $0.75 \mathrm{~kW}$ and rated voltage is $200 / 220 \mathrm{~V}$, the number of poles is 2, 4 and 6 . In general bearings can be used until rolling fatigue life if they are handled properly, but bearing life is shortened by damage resulting from faulty selection, handling, lubrication and sealing, etc.

Because it is not possible to retrieve aging deteriorated

Table 1. Specification of induction motor and ball bearing

\begin{tabular}{|c|c|c|c|}
\hline Motor & \multicolumn{3}{|c|}{ Three phase induction motor } \\
\hline $\begin{array}{c}\text { Rated output } \\
\text { power }\end{array}$ & \multicolumn{3}{|c|}{$0.75 \mathrm{~kW}$} \\
\hline Rated voltage & \multicolumn{3}{|c|}{$200 / 220 \mathrm{~V}$} \\
\hline Pole & 2 pole & 4 pole & 6 pole \\
\hline Bearing & O.S. 6203 & O.S. 6203 & O.S. 6204 \\
& L.S. 6204 & L.S. 6204 & L.S. 6205 \\
\hline
\end{tabular}

bearings on site at production plants, for our experiment we simulated bearing faults by artificially contaminating bearings with foreign matter. The contamination with foreign matter caused abrasion on the rolling surface of the bearings, intensifying bearing damage. Furthermore, this damage generated jamming and touched off plastic deformation. The progress of deterioration accelerated because localized stress concentration was induced by the formation of pits.

2.2 Contaminated Bearings We selected WHITE MORUNDUM (Showa Denko) as the substance for contaminating bearings. WHITE MORUNDUM is a high-purity white electrofused-alumina abrasive material. According to Yamashita ${ }^{(19)}$, the main chemical composition of the dust that blows around roadways is $\mathrm{SiO}_{2}, \mathrm{Al}_{2} \mathrm{O}_{3}, \mathrm{Fe}_{2} \mathrm{O}_{3}, \mathrm{CaO}, \mathrm{MgO}$, $\mathrm{TiO}_{2}$. Therefore, we selected WHITE MORUNDUM, which contains $\mathrm{Al}_{2} \mathrm{O}_{3}$, the hardest component of dust, for accelerated aging. We used \#100 granules with an average granule diameter of $106-125 \mu \mathrm{m}$. First, we measured $20 \mathrm{mg}$ of WHITE MORUNDUM using a digital scale, and poured it on the outer ring rolling surface of the bearings. When we rolled the contaminated bearings manually immediately after contamination, we could feel that they were catching with each rotation. After manually rolling the bearings from 20 to 30 times, we installed them in the motor.

\section{Experimental Setup}

Figure 1 shows the experimental setup for measuring motor (standard three-phase induction motor) current. We measured the phase current in the three phases using a current probe (HIOKI3274), and recorded it in a MEMORY HiCORDER (YOKOGAWA DL750). The A/D resolution of the measuring device is $12 \mathrm{bit}$, and the frequency band is DC $10 \mathrm{MHz}(-3 \mathrm{~dB})$. We analyzed the measured current, and calculated the stator current power spectral density. We applied the Hanning window function when there were changes in frequency, and performed averaging processing multiple times in order to improve the $S / N$ ratio further.

We obtained the normal data for this experiment using a brand new motor shipped from the motor manufacturer as the normal motor. Also, we obtained abnormal data from a motor with contaminated bearings installed as the abnormal motor.

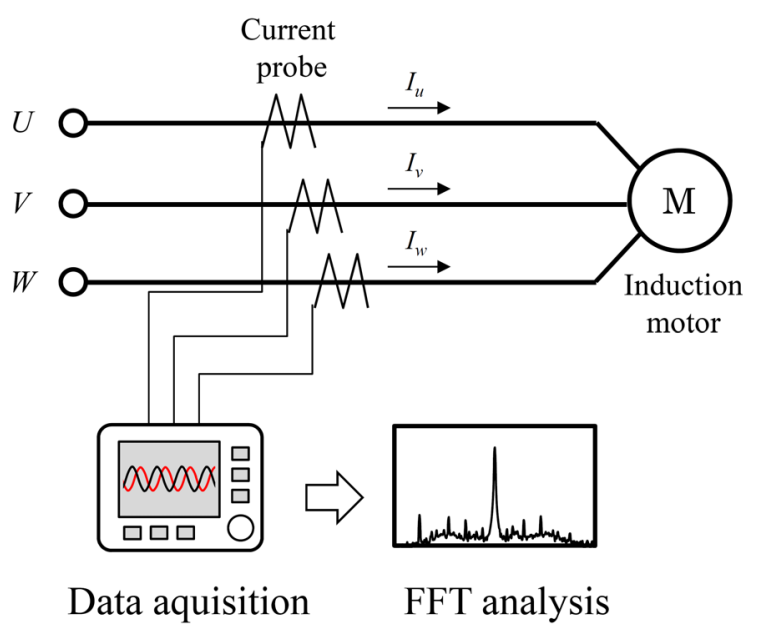

Fig. 1. Experimental setup 


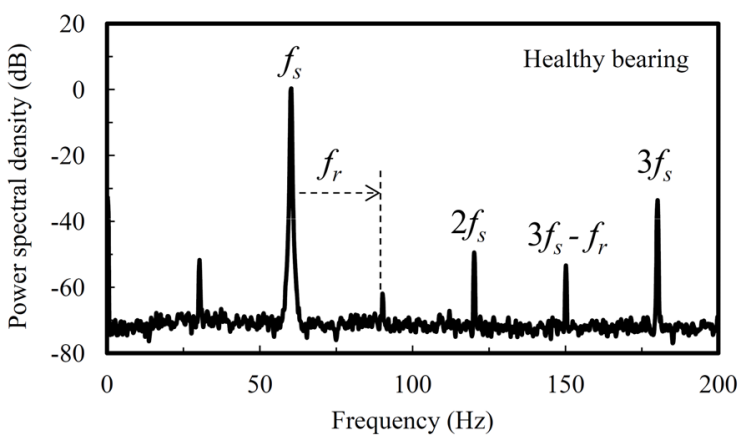

Fig. 2. Stator current spectrum of unloaded induction motor with a healthy bearing

\section{Experimental Results}

4.1 Stator Current Power Spectral Density Characteristics of Normal Motors Figure 2 shows the stator current power spectral density of a normal motor that is running without a load. Figure 2 shows the sideband wave $\left(f_{s}\right.$ $\pm f_{r}: 60 \pm 30 \mathrm{~Hz}$ ) caused by power frequency $f_{s}: 60 \mathrm{~Hz}$, and its harmonics $\left(2 f_{s}: 120 \mathrm{~Hz}, 3 f_{s}: 180 \mathrm{~Hz}\right)$ and rotational frequency $f_{r}: 30 \mathrm{~Hz}$. Rotational frequency $f_{r}$ is calculated using the following formula.

$$
f_{r}=f_{s} \cdot \frac{2(1-s)}{p}
$$

Here, $s$ indicates slippage, and $p$ is the number of poles. When there are four poles, it is approximately $30 \mathrm{~Hz}$ when there is no load. Since the motor was driven at a commercial power frequency of $60 \mathrm{~Hz}$, the sidebands appeared on either side equally with the power frequency of $60 \mathrm{~Hz}$ at the center, since the current receives amplitude modulation. Current amplitude modulation is generated because every revolution of the motor axis affects the spatial magnetic field lines in the air gap between the stator and the rotor. Therefore, abnormalities are easier to detect in motors structured with small air gaps than in motors with large air gaps, since the effect on spatial magnetic field lines is relatively larger. Normal motors have stable stator current power spectral density that does not change during approximately three hours of operation. Furthermore, the stator current power spectral density results of phases $U, V$ and $W$ match.

4.2 Stator Current Power Spectral Density Characteristics of Abnormal Motors We installed contaminated bearings in a motor and performed measurements using the same methods described in the previous section. As soon as the motor started running, it emitted a loud noise. Approximately 10 minutes after it started running, the noise changed to the shrill, high-pitched sound of metal friction. Normally an oil film forms between a rolling element and the inner and outer rings. The rolling element rotates while rolling over the surface of an oil film with low friction. The contamination, however, causes abrasion to occur and triggers metal-tometal contact.

Next, Fig. 3 shows the results of calculation of U-phase stator current power spectral density. Figure 3 shows wave forms 230 minutes after the motor started running. Unlike the normal motor, sidebands of $60 \pm 11.7 \mathrm{~Hz}$ and $60 \pm$ $18.0 \mathrm{~Hz}$ can be observed on either side, with the $60 \mathrm{~Hz}$ power

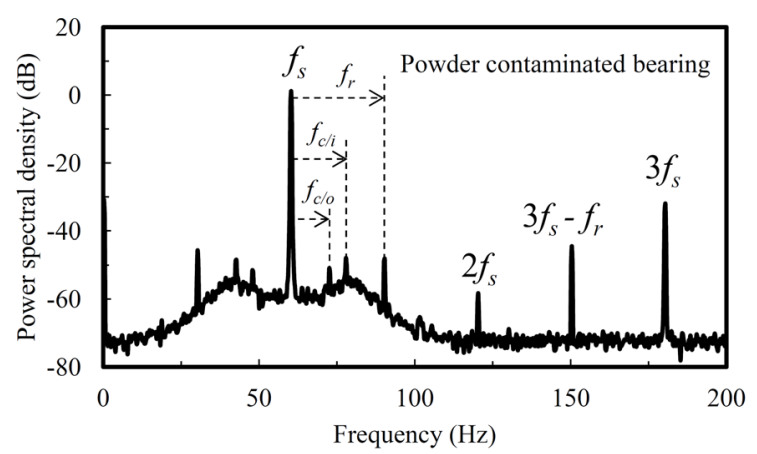

Fig. 3. Stator current spectrum of unloaded induction motor with a powder contaminated bearing

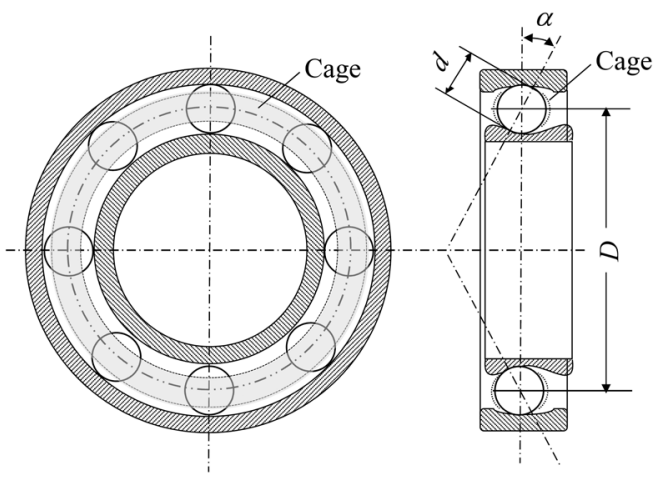

Fig. 4. Ball bearing dimension

frequency in the center.

The sidebands are only near $60 \mathrm{~Hz}$. Sidebands near $120 \mathrm{~Hz}$ or $180 \mathrm{~Hz}$ could not be observed. This is because the signal strength gets weaker the closer it gets to the harmonic area.

When bearing damage occurs, load ripples that are equivalent to the vibrational frequency of the bearings are triggered, causing current amplitude modulation, and sidebands described in Formulas (2) to (6) appear with the $60 \mathrm{~Hz}$ power frequency at the center ${ }^{(2)(20)}$.

$$
\begin{aligned}
& f_{c / o}=\frac{f_{r}}{2}\left(1-\frac{d}{D} \cos \alpha\right) \approx 0.4 f_{r} \ldots \ldots \ldots \ldots \ldots \ldots \\
& f_{c / i}=\frac{f_{r}}{2}\left(1+\frac{d}{D} \cos \alpha\right) \approx 0.6 f_{r} \ldots \ldots \ldots \ldots \ldots \ldots \\
& f_{o}=\frac{N \cdot f_{r}}{2}\left(1-\frac{d}{D} \cos \alpha\right) \approx 0.4 \cdot N \cdot f_{r} \ldots \ldots \ldots \ldots \\
& f_{i}=\frac{N \cdot f_{r}}{2}\left(1+\frac{d}{D} \cos \alpha\right) \approx 0.6 \cdot N \cdot f_{r} \ldots \ldots \ldots \ldots \\
& f_{b}=\frac{f_{r} \cdot D}{d}\left(1-\frac{d^{2}}{D^{2}} \cos ^{2} \alpha\right) \ldots \ldots \ldots \ldots \ldots \ldots
\end{aligned}
$$

Here, $f_{c / o}$ : cage defect frequency relative to outer ring; $f_{c / i}$ : cage defect frequency relative to inner ring; $f_{o}$ : outer ring defect frequency; $f_{i}$ : inner ring defect frequency; $f_{b}$ : rolling element defect frequency; $D$ : bearing pitch diameter; $d$ : rolling element diameter, $\alpha$ contact angle and $N$ : number of rolling elements. These parameters are determined by the bearing structure in Fig. 4. Also, rotational frequency $f_{r}$ is determined by Formula (1). The sidebands that were observed (60 $\pm 11.7 \mathrm{~Hz}$ and $60 \pm 18.0 \mathrm{~Hz}$ ) match (19) with the damaged cage frequency band, Formulas (2) and (3), calculated based 


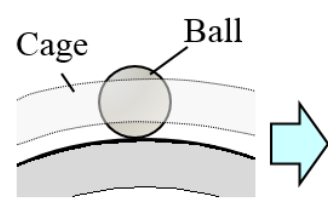

Normal

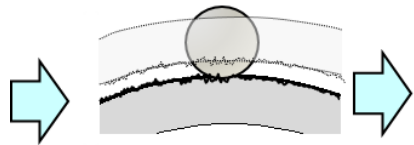

Bearing wear

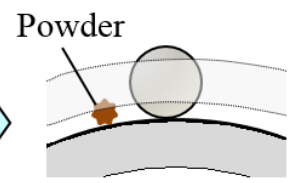

Powder contaminated

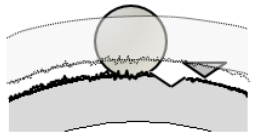

Flaking
Fig. 5. Degradation process of powder contaminated bearing

on the bearing specifications. Also, observing the sidebands $\left(f_{s} \pm f_{r}\right)$ of the rotational frequency band of power frequency $f_{s}$ shown in Fig. 3, compared to their normal state, when the bearings were contaminated, the signal strength in the $30 \mathrm{~Hz}$ band increased $6.1 \mathrm{~dB}$, and the signal strength in the $90 \mathrm{~Hz}$ band increased $13.4 \mathrm{~dB}$.

The reason for the increases in signal strength in the natural frequency band and rotational frequency band of the bearings is explained in Fig. 5. Figure 5 shows the degradation process of the contaminated bearings. If bearings are contaminated with foreign matter, load rippling is generated by foreign substances jammed between the cage and the bearing inner ring or between the cage and the bearing outer ring. The vibrational frequency of load ripples is equivalent to the frequency of the cage damage. This increases the signal strength in the natural frequency band of the bearings.

When the rolling element passes over the inner bearing ring and the rolling surface of the outer ring over and over, the foreign matter accelerates the wear. This increases the amount of wear on the rolling surface, and the gaps inside the bearings are enlarged by the flaking that is triggered. When the gaps inside the bearings are enlarged, the axis of the motor's rotor touches off dynamic eccentricity, and causes fluctuations in the air gaps between the stator and the rotor. This variable cycle is determined by the cycle of the motor axis making a single revolution, so it matches the rotational frequency of the motor. Therefore, the increase in the dynamic eccentricity associated with the enlargement of the gap inside the bearings causes the increase in signal strength in the rotational frequency band.

From the above, and the results of our observation of the process of bearing degradation, an effective method for detecting bearing faults is to monitor the signal strength in the natural frequency band and rotational frequency band of bearings.

\subsection{Effect of the Number of Poles in the Motor}

Since the number of poles in motors differs according to the mechanical equipment in which they are used, bearing faults must be detected independently of the number of poles. Here, we installed contaminated bearings in three types of motors with different numbers of poles, and validated bearing fault detection performance. Since there is an inverse proportion between the number of poles in a motor and the rotational
Table 2. Bandwidth region of stator current spectrum

\begin{tabular}{|c|c|c|}
\hline \multirow{2}{*}{} & \multicolumn{2}{|c|}{ Powder contaminated bearing } \\
\cline { 2 - 3 } 2 pole & $f_{c / o}$ & $f_{c / i}$ \\
\hline \multirow{2}{*}{4 pole } & $\begin{array}{c}\text { Can be detected } \\
(24 \mathrm{~Hz})\end{array}$ & Cannot be detected \\
\hline 6 pole & $\begin{array}{c}\text { Can be detected } \\
(8 \mathrm{~Hz})\end{array}$ & $\begin{array}{c}\text { Can be detected } \\
(18 \mathrm{~Hz})\end{array}$ \\
\hline
\end{tabular}

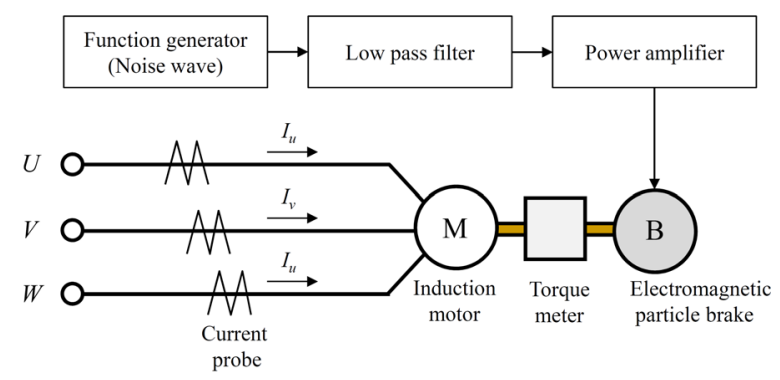

Fig. 6. Experimental setup for variable load conditions

frequency, Formula (1) was used to calculate the rotational frequency of the motors with each of the different number of poles. In unloaded state, two pole was approximately $60 \mathrm{~Hz}$, four pole was approximately $30 \mathrm{~Hz}$ and 6 pole was approximately $20 \mathrm{~Hz}$.

Table 2 shows the bandwidth region of stator current spectrum results. For each of the 2 pole, 4 pole and 6 pole contaminated bearings, both $f_{c / o}$ and $f_{c / i}$ and in either or including one frequency band the signal strength of stator current power spectral density increased.

From this, the cage damage frequency band shown Formulas 2 and 3 appeared, regardless of number of poles. Therefore, it is possible to detect bearing faults by identifying the number of poles in the motor.

However, an issue exists in the case of two poles, since in unloaded state, the rotational frequency band occurs in the $120 \mathrm{~Hz}$ band, so it overlaps with the secondary higher harmonic of the power frequency. Therefore, the rotational frequency band cannot be used as the monitoring frequency for two poles. Under actual loading slipping is generated, so there is a tiny amount of shift in the rotational frequency band from $120 \mathrm{~Hz}$, which is the amount of the slipping. Therefore, it is possible to detect bearing faults in two pole motors, but only in loaded state.

4.4 Effect of Variable Loads We created the experimental setup shown in Fig. 6 to evaluate the effect of load variation on stator current power spectral density. It has been reported ${ }^{(18)}$ that frequency variations of under $6-7 \mathrm{~Hz}$ occur when mixers, which are examples of motors with large load variations, are running.

Here, we investigated the stator current power spectral density when a load variation of under $10 \mathrm{~Hz}$ was applied while the motor was running. In order to apply load variation, we 


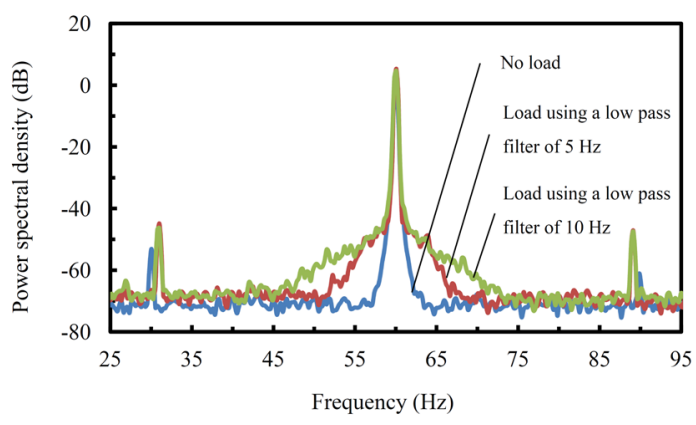

Fig. 7. Stator current spectrum of induction motor at the variable load conditions

controlled the current to an electromagnetic particle brake (MITSUBISHI ELECTRIC ZKB-1.2XN). In order to simulate random load variations, we generated noise wave forms from a function generator (Agilent 33120A), and used a low pass filter (NF Electronic FV-628B) to create noise waveforms that included only low frequency components. Then we amplified the signal using a power amp (NF Electronic4025), input a random current signal in the order of several $\mathrm{Hz}$ into the electromagnetic particle brake, and varied the load.

Figure 7 shows the stator current power spectral density during load variations. The following formula was used for the load torque during load variation.

$$
T_{\text {load }}(t)=T_{0}+T_{\text {osc }} \cos \left(2 \pi f_{\text {rdm }} t\right) \ldots \ldots \ldots \ldots \ldots \ldots(7)
$$

$T_{\text {load }}(t)$ : load torque; $T_{0}$ : average torque; $T_{\text {osc }}$ : vibration component of load torque; $f_{r d m}$ : load torque frequency. When random load variations occur, driving current equivalent to the load torque in the right side of Formula 7 varies, so a broad spectra equivalent to load torque frequency $f_{r d m}$ near power frequency $f_{s}$ is superimposed. The spectral width is determined by the load variation frequency. In any case, for random load variations, sharp peaks are not observed in the region of the bearings' natural frequency band, as shown in (2) and (3).

Next, observing the rotational frequency band, the signal strength increases when the load variation increases. This is because the increase in load variation increases the current, and as a result the spatial magnetic field lines in the air gap between the stator and the rotor expand. Also, slipping occurs due to the load variation, and this varies the position of the rotational frequency band.

From the above, it is possible to avoid the effect of load variation characteristics and detect bearing faults by detecting only the line spectral peak in the bearing natural frequency band region, and monitoring the signal strength of the rotational frequency band from a fixed load standard.

\section{Validation of Diagnostic Method}

5.1 Sideband Peak Detection Detect the spectral peak by performing a differential operation on the spectral data. In order not to misdetect spectral peaks caused by noise, it is possible to detect spectral peaks using as a condition that the result of the differential operation must be a value within a specified range. After detecting the spectral peak, evaluate the sidebands in order to identify abnormal frequency

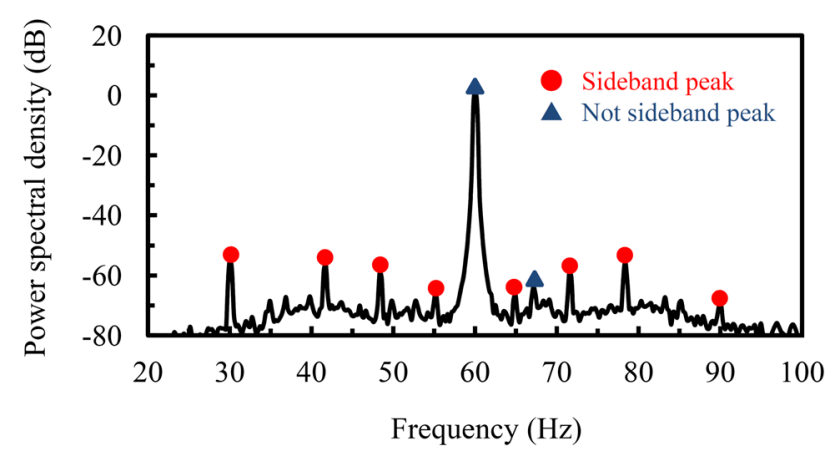

Fig. 8. Detection of sideband caused by faulty bearing

bands. When bearing faults occur, sidebands are always generated by current modulation, with the power frequency at the center. Evaluation of the sidebands improves the accuracy of judgment of abnormal frequency bands. For example, in Fig. 8 the waveforms marked with are sideband waves, and the ones marked with $\boldsymbol{\Delta}$ are not sideband waves.

Spectral peaks are detected in the $66.9 \mathrm{~Hz}$ band, but on the bottom side where the power frequency $60 \mathrm{~Hz}$ is the center, $53.1 \mathrm{~Hz}$, which is equivalent to a sideband of $66.9 \mathrm{~Hz}$, is not generated. Spectra are generated with bearing faults due to amplitude modulation of power frequencies, so a pair of sidebands will always be generated. Here, sidebands are evaluated from the center of the peak point, using the following formula (8). The frequency band of the sideband wave on the bottom side is $f_{b l}$, and the frequency band of the sideband wave on the top side is $f_{b h}$. FFT is performed at $N$ point in relation to sampling speed $S_{v} \mathrm{~S} / \mathrm{s}$, so the minimum frequency resolution is $S_{v} / N \mathrm{~Hz}$. Sample the frequency band $f_{b l}$ and $f_{b h}$ that satisfy the following formula.

$$
\left|\left(f_{b l}+f_{b h}\right) / 2-f_{s}\right| \leq \frac{S_{v}}{N}
$$

5.2 Diagnostic Method Based on the results so far, the bearing fault diagnostic method is shown in Fig. 9. First, use a current sensor as a data acquisition part, and acquire current from any of the three phases.

A good time to acquire the current is when there is constant load.

Also, it is preferable to use a current sensor for measurement that has only a small margin of error for noise, since it will be detecting minute signal strengths. The data acquisition time is determined by the sampling speed and the minimum frequency resolution. A resolution that enables observation of line spectra is preferable. Data processing is performed by FFT analysis and sideband peak detection. Detect only the sideband peaks. Spectral peaks caused by noise must not be detected by mistake. In order to avoid misdetection, judge by whether or not the sideband peak matches the theoretical peak of the bearings' natural frequency band or rotational frequency band. When matching the theoretical peak, monitor the relevant signal strength. Then, judge the threshold value of the monitoring frequency band signal strength. Since there is individual variability in each motor, it is not possible to determine a threshold value uniquely. Here, to determine the threshold value, use the standard deviation of normal data $\sigma$. This experimental setup uses the standard deviation of the power spectral density of a normal motor. 


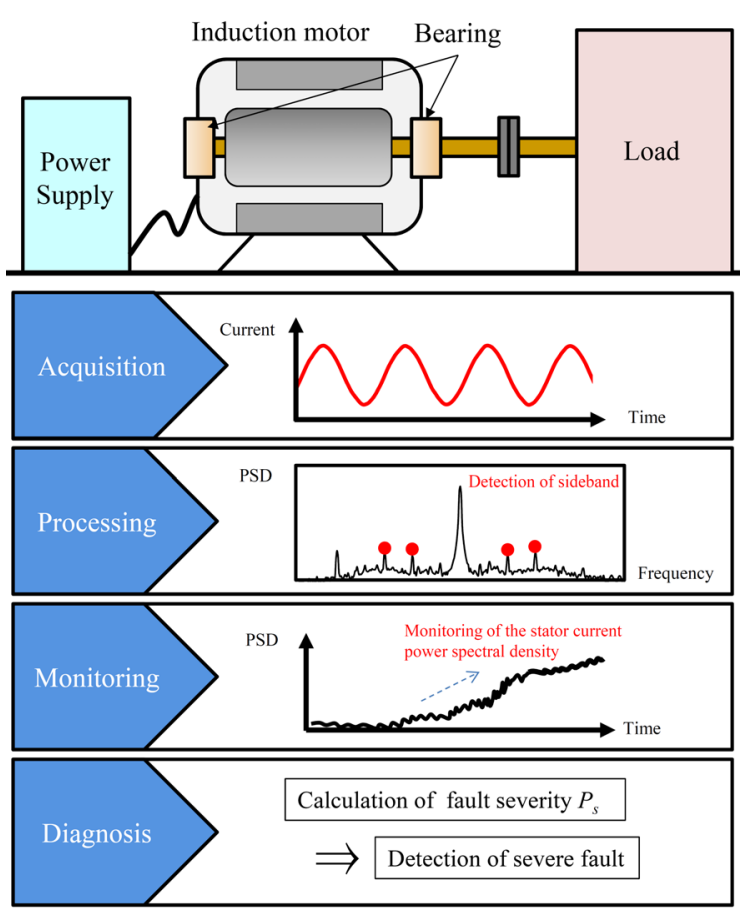

Fig. 9. Algorithm for bearing fault detection

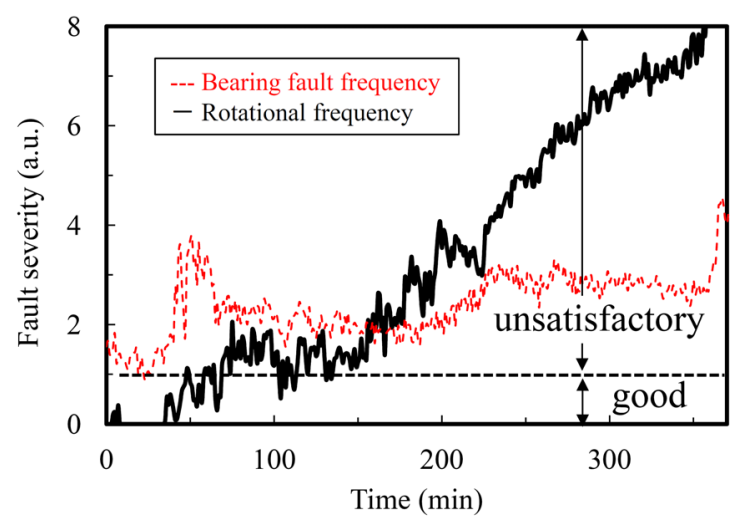

Fig. 10. Transient fault severity of bearing fault frequency and rotational frequency bands of unloaded induction motor with a powder contaminated bearing

Analysis after running for three hours resulted in an $\sigma$ of $1.25 \mathrm{~dB}$. Here, a discrepancy of $3 \sigma(3.75 \mathrm{~dB})$ from the normal value is set as severity level 1 (Ps1). Therefore, a signal strength of $99.73 \%$ of a normal motor indicates severity level 1. Because the signal strength of a heavily loaded motor will increase even under normal conditions, the threshold value must be set so that there is no risk of detection mistakes.

5.3 Validation Results We poured $20 \mathrm{mg}$ of WHITE MORUNDUM on the outer ring rolling surface of the bearings, and installed the bearings in the motor. Then we ran the motor continuously for approximately 6 hours, retrieving data in one-minute intervals. Since the motor was run without a load, load variations did not occur.

Figure 10 shows the results of calculation of the severity level of the signal strength of the bearings' natural frequency band and rotational frequency band in the motor. The severity level of the bearings' natural frequency band was 1.5 at the stage when the motor started rotation. It increased to a maximum of 3.8 after 51 minutes had elapsed. We believe that it will be possible to detect bearing faults at the stage when the bearings are contaminated.

Meanwhile, observing the signal strength of the rotational frequency band, after 35 minutes elapsed the severity level increased with time. This indicates that if bearings are abraded by foreign matter, the damage becomes severe and the vibration in the bearings becomes stronger, and the air gap fluctuates widely, affecting the current value. Therefore, the signal strength of the rotational frequency band becomes an evaluation criteria equivalent to the axis eccentricity due to faulty bearings. Because of the fact that bearing eccentricity increases over time due to abrasion on the rolling surface, by monitoring the signal strength of the rotational frequency band it is possible to detect changes in eccentricity associated with faulty bearings. From the fact that a signal strength of $99.73 \%$ of a normal motor indicates severity level 1 it is possible to judge faults greater than severity level 1 .

In this experiment, the severity level increased to over 4 $(12 \sigma)$ in the bearings' natural frequency band 370 minutes after the motor started running, and the severity level increased to over $8(24 \sigma)$ in the rotational frequency band. When the bearings were contaminated with foreign matter, the radial gaps in the bearings widened due to the friction with this foreign matter. As a result of the axis eccentricity that occurred, the rotors caused axial runout and the rotors and stators started colliding. Collision deformation sites were also confirmed on the stators and rotors.

Based on the above, as a result of validating the suitability of the proposed method, which used a motor with accelerated degradation using contaminated bearings, we were able to detect faults at the contamination stage and to detect changes in eccentricity that are associated with bearing faults by monitoring both the bearings' own natural frequency band and their rotational frequency band.

\section{Summary}

The purpose of this study was to identify the current signal frequency band that is effective for bearing deterioration diagnosis and to validate a proposed diagnostic method. Contaminated bearings were manufactured and installed in a motor, and the stator current power spectral density was examined when the motor was running. The results confirmed that when there was damage to the cage near the power frequency fs, there were increases in the signal strength of the sideband waves that matched the vibrational frequency band and there was an increase in the signal strength of the rotational frequency band. Furthermore, we performed a similar test on motors with a different number of poles, and demonstrated that it was possible to detect signals from the desired frequency band. Also, from the load variation characteristics we demonstrated that the adverse effects of load variations can be avoided by detecting sharp spectral peaks and monitoring steady load standards. Based on these experimental results, we devised a diagnostic method and validated it using a motor with accelerated wear. The results showed that by monitoring both the bearing's own natural frequency and its rotational frequency, it is possible to detect abnormalities at the contamination stage and to detect the changes in eccentricity that are associated with bearing faults, thereby demonstrating the utility of this method. 


\section{References}

( 1 ) P. Zhang, Y. Du, T.G. Habetler, and B. Lu: "A Survey of Condition Monitoring and Protection Methods for Medium-Voltage Induction Motors", IEEE Trans. on Industry Applications, Vol.47, No.1 (2011)

( 2 ) T. Toyoda: "Procedure of diagnosis for rotary machine", JIPM solution (2009) (in Japanese)

( 3 ) R.R. Schoen, T.G. Habetler, F. Kamran, and R.G. Bartfield: "Motor bearing damage detection using stator current monitoring", IEEE Trans. on Industry Applications, Vol.32, pp.1274-1279 (1995)

( 4 ) R.R. Schoen and T.G. Habetler: "Effects of Time-Varying Loads on Rotor Fault Detection in Induction Machines", IEEE Trans. on Industry Applications, Vol.31, No.4, pp.900-906 (1995)

( 5 ) L. Eren and M.J. Devaney: "Bearing Damage Detection via Wavelet Packet Decomposition of the Stator Current", IEEE Trans. on Instrumentation and Measurement, Vol.53, No.2, pp.431-436 (2004)

( 6 ) J.R. Stack, T.G. Habetler, and R.G. Harley: "Fault Classification and Fault Signature Production for Rolling Element Bearings in Electric Machines", IEEE Trans. on Ind. Appli., Vol.40, No.3, pp.735-739 (2004)

( 7 ) C. Kar and A.R. Mohanty: "Monitoring gear vibrations through motor current signature analysis and wavelet transform", Mechanical Systems and Signal Processing, Vol.20, pp.158-187 (2006)

( 8 ) J.-H. Jung, J.-J. Lee, and B.-H. Kwon: "Online Diagnosis of Induction Motors Using MCSA", IEEE Trans. on Industrial Electronics, Vol.53, No.6, pp.1842-1852 (2006)

( 9 ) A. Bellini, F. Filippetti, C. Tassoni, and G.-A. Capolino: "Advances in Diagnostic Techniques for Induction Machines", IEEE Trans. on Industrial Electronics, Vol.55, No.12, pp.4109-4126 (2008)

(10) M. Blödt, P. Granjon, B. Raison, and G. Rostaing: "Models for Bearing Damage Detection in Induction Motors Using Stator Current Monitoring", IEEE Trans. on Industrial Electronics, Vol.55, No.4, pp.1813-1822 (2008)

(11) A. Widodo, B.-S. Yang, D.-S. Gu, and B.-K. Choi: "Intelligent fault diagnosis system of induction motor based on transient current signal", Mechatronics, Vol.19, pp.680-689 (2009)

(12) M.R. Mehrjou, N.M.H. Marhaban, and N. Misron: "Rotor fault condition monitoring techniques for squirrel-cage induction machine-A review", Mechanical Systems and Signal Processing, Vol.25, pp.2827-2848 (2011)

(13) V. Hegdea and G.S. Maruthi: "Experimental investigation on detection of air gap eccentricity in induction motors by current and vibration signature analysis using non-invasive sensors", Energy Procedia, Vol.14, pp.1047-1052 (2012)

(14) M. EI H. Benbouzid: "A review of induction motors signature analysis as a medium of fault detection", IEEE Trans. on Industrial Electronics, Vol.47, No.5, pp.984-993 (2000)

(15) M. Djeddi, P. Granjon, and B. Leprettre: "Bearing fault diagnosis in Induction Machine based on current analysis using high resolution technique", IEEE International Symposium on Diagnostics for Electric Machines, Power Electronics and Drives, pp.1-6 (2007)

(16) I. Yilmaz Ö̈el and M. El H. Benbouzid: "Induction motor bearing failure detection and diagnosis: Park and Concordia transform approaches comparative study", IEEE/ASME TRANSACTIONS ON MECHATRONICS, Vol.13, No.2, pp.257-261 (2008)

(17) J. Zarei and J. Poshtan: “An advanced Park's vectors approach for bearing fault detection", Tribology International, Vol.42, pp.213-219 (2009)

(18) T. Seto: "Diagnosis method using frequency analysis of motor current in induction machine", Plant engineer, Vol.43, No.3, pp.33-41 (2011) (in Japanese)
(19) K. Yamashita: "On the Road Dust", Powder Technology, Vol.2, No.3, pp.366-376 (1965) (in Japanese)

(20) Dr. S.J. Lacey: "An Overview of Bearing Vibration Analysis", Maintenance \& Asset Management, Vol.23, No.6, pp.32-42 (2008)

Makoto Kanemaru (Member) Ph.D., Department of Electrical and

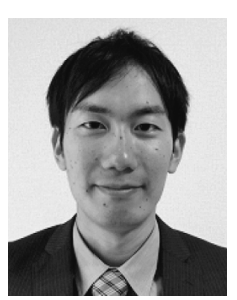
Electronic Engineering, Graduate School of Engineering, Tokyo Institute of Technology, March 2011. He has been a researcher at Mitsubishi Electric Corporation since April 2011. His primary research focus is motor malfunction diagnosis technology. He is currently a member of the Mitsubishi Electric Advanced Technology R\&D Center, Electromechanical Systems Department, Switching Device Group. He is a member of the Japan Society of Mechanical Engineers, Institute of Electrical Installation Engineers of Japan and the Society of Plant Engineers Japan.

Mitsuru Tsukima (Member) M.Sc., Department of Applied Physics,

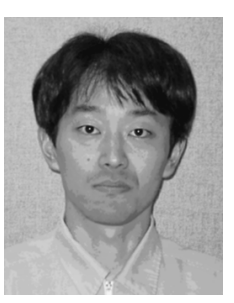
Graduate School of Engineering, Osaka University, March 1996. From April 1996 to March 2017, he worked at the Mitsubishi Electric Advanced Technology R\&D Center. Since April 2017 he has been a professor of electronics and mechanical engineering in the Faculty of Engineering, Osaka ElectroCommunication University. His primary focus is research and development of actuators and arc discharge. He holds a Ph.D. in Engineering.

Toshihiko Miyauchi (Non-member) has been a researcher at

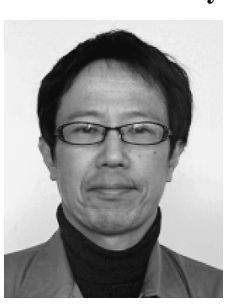
Mitsubishi Electric Corporation since April 1983. His primary focus is on design and development at the Mitsubishi Electric Motor Control Center. He is currently a member of the Mitsubishi Electric Power Distribution Systems Manufacturing Office, Control Center Manufacturing Department, Electronic System and Device Design Section.

Kazufumi Hayashi (Non-member) M.Sc., Graduate Faculty of Engi-

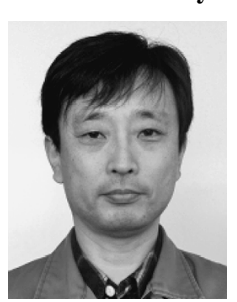
neering, Okayama University, March 1996. He has been a researcher at Mitsubishi Electric Corporation since 1996. His primary focus is on design and development at the Mitsubishi Electric Motor Control Center. He is currently a member of the Mitsubishi Electric Power Distribution Systems Manufacturing Office, Control Center Manufacturing Department, Control Center Design Section. 